\title{
IMPLEMENTASI PELAYANAN TERPADU SATU PINTU DALAM MEWUJUDKAN PELAYANAN PRIMA DI KABUPATEN TRENGGALEK \\ *Berlian Tyasotyaningarum ${ }^{1)}$, Arsita Putri Winanti ${ }^{2)}$ \\ ${ }^{1,2)}$ Administrasi Publik, Fakultas Ilmu Sosial dan Ilmu Politik, Universitas Kediri, Indonesia
}

*Email Korespondensi : berlian.tyasotyaningarum@unik-kediri.ac.id

\begin{abstract}
Abstrak
Penelitian ini menggunakan metode kualitatif, penelitian ini digambarkan secara jelas dan mendetail terkait implementasi (PTSP) dalam mewujudkan pelayanan prima di Dinas Penanaman Modal Dan Pelayanan Terpadu Satu Pintu Kabupaten Trenggalek. Data diperoleh dari sumber primer dan sekunder. Informan dalam penelitian ini terdiri dari empat (4) informan kunci, tiga (3) informan pendukung, dan adapun teknik pengumpulan data dalam penelitian ini dengan observasi, wawancara, dokumentasi. Hasil penelitian menunjukan secara keseluruhan Implementasi PTSP di Dinas Penanaman Modal Dan Pelayanan Terpadu Satu Pintu untuk kepengurusan pelayanan perizinan sudah dilakukan sesuai dengan SOP dan regulasi yang ada. Komunikasi yang dilakukan antar atasan dan bawahan tentang implementasi juga sudah sesuai dengan aturan, dan komukasi yang dilakukan dengan masyarkat pun juga sudah menyeluruh. Serta untuk waktu penyelesaian, dan biaya terkait pelayanan perizinan juga sudah diatur sesuai dengan SOP yang sudah berlaku. Dilengkapi juga berbagai fasilitas yang lengkap yang ada di Dinas Penanaman Modal Dan Pelayanan Terpadu Satu Pintu sebagai penunjang kepuasan dan kenyamanan masyarakat.
\end{abstract}

Kata Kunci: Implementasi Progam, PTSP, Pelayanan Prima.

\begin{abstract}
This study uses a qualitative method, this research is described clearly and in detail related to the implementation (PTSP) in realizing excellent service at the Office of Investment and One Stop Integrated Services, Trenggalek Regency. Data obtained from primary and secondary sources. The informants in this study consisted of four (4) key informants, three (3) supporting informants, and the data collection techniques in this study were observation, interviews, and documentation. The results of the study show that the overall implementation of PTSP in the Office of Investment and One Stop Integrated Services for the management of licensing services has been carried out in accordance with existing SOPs and regulations. Communication between superiors and subordinates regarding implementation is also in accordance with the rules, and communication with the community is also comprehensive. As well as for the completion time, and costs related to licensing services have also been regulated in accordance with the SOP that is already in effect. It is also equipped with various complete facilities available at the Investment
\end{abstract}


Service and One-Stop Integrated Service as a support for community satisfaction and comfort.

Keywords: Program Implementation, PTSP, Excellent Service.

\section{PENDAHULUAN}

Keadaan pelayanan publik di Indonesia masih mengalami berbagai masalah, dimana masih banyak ditemukan keluhan dari masyarakat terkait pelayanan publik. Sebagai solusi permasalahan tersebut, pemerintah menerapkan PTSP sebagai salah satu cara untuk merubah proses pelayanan publik yang sederhana, cepat, dan tepat sasaran (Ginting dkk, 2018). Kabupaten Trenggalek merupakan kawasan daerah yang telah menerapkan inovasi sistem Pelayanan Terpadu Satu Pintu (PTSP). Dengan inovasi tersebut Kabupaten Trenggalek di anugerahi juara 1 Pelayanan Terpadu Satu Pintu (PTSP) pada lomba inovasi daerah oleh pemerintah pusat (Supriyatno, 2020). Dengan demikian penelitian ini penting dilakukan karena PTSP di Kabupaten Trenggalek berdampak dapat meningkatkan kualitas pelayanan publik dan sekalogus meningkatkan kepuasan kepada masyarakat.

Negara berkewajiban memberikan pelayanan kepada setiap warga negara dan penduduk dalam memenuhi kebutuhan dasar. Peran pemerintah sebagai penyedia layanan publik harus memberikan pelayanan yang sebesar-besarnya. Karena hal ini adalah hasil dari kehidupan bernegara dan berbangsa dalam bentuk Negara Republik. Kebutuhan dasar manusia semakin hari semakin meningkat dengan adanya tingkat peradaban manusia. Seperti pendapat Rochmawan dalam (Gunawijaya, 2017) kebutuhan manusia banyak serta 
beranekaragam, bahkan tidak hanya beranekaragam tetapi bertambah terus tidak ada habisnya sejalan dengan perkembangan peradaban dan kemajuan ilmu pengetahuan dan teknologi. Oleh karena itu kualitas pelayanan perlu terus ditingkatkan untuk mencapai pelayanan publik yang prima.

Pemerintah melalui Kementrian Dalam Negeri (Kemendagri) menyelenggarakan progam inovasi daerah, sebagai upaya peningkatan edukasi dan sosialisasi penerapan kebiasaan baru oleh setiap daerah. Seperti contoh yang telah menerapkan inovasi daerah melalui program PTSP yaitu Kabupaten Trenggalek. Dengan adanya penerapan inovasi tersebut Kabupaten Trenggalek pada lomba inovasi daerah tingkat Jawa Timur dapat meraih penghargaan sebagai juara pertama (1) pelayanan terpadu satu pintu. Pemerintah Kabupaten Trenggalek mengikuti lomba inovasi daerah tersebut, bukan semata mata hanya ingin mendapatkan penghargaan, tetapi sebagai acuan agar dapat diterapkan di kehidupan masyarakat Kabupaten Trenggalek yang produktif, aman, nyaman dan terbebas dari penularan Covid-19. Salah satu cara yang dilakukan dengan mengumpulkan semua stakeholder guna menyamakan tujuan. Jika semua tidak saling membantu dalam penanganan Covid-19 maka semua kegiatan akan terhambat, dikarenakan jika semua stakeholder saling bergotong royong maka proses pelayanan akan berjalan dengan lancar (Widodo, 2020).

Kabupaten Trenggalek melalui DPMPTSP sudah melaksanakan PTSP sejak tahun 2006. Dengan demikian PTSP di Kabupaten Trenggalek sudah berlangsung selama 15 tahun. PTSP di Kabupaten Trenggalek sudah dilaksanakan dengan baik hal ini terbukti dengan diperolehnya prestasi juara pertama (1) pelayanan terpadu satu pintu dalam lomba inovasi daerah tingkat Jawa Timur (Widodo, 2020). Berdasarkan pernyataan tersebut, menunjukkan bahwa penelitian PTSP penting dilakukan untuk mengetahui bagaimana implementasi PTSP itu sendiri terhadap kualitas pelayanan publik yang sangat berdampak pada kepuasan masyarakat. Oleh sebab itu pentingnya untuk diketauhi peran PTSP di Kabupaten Trenggalek dalam mewujudkan pelayanan publik yang prima. Dengan demikian penelitian ini dilakukan untuk mengidentifikasi bagaimana impelementasi PTSP 
di Kabupaten Trenggalek dapat mewujudkan pelayanan prima. Oleh sebab itu, rumusan masalah dalam penelitian ini adalah implementasi pelayanan terpadu satu pintu (PTSP) di Kantor Dinas Penanaman Modal Dan Pelayanan Terpadu Kabupaten Trenggalek.

\section{TINJAUAN PUSTAKA}

\section{Konsep Pelayanan Publik}

Pendapat Grindle dalam (Akib, 2010) implementasi adalah proses umum tindakan administrative yang dapat diteliti di tingkat progam tertentu. Proses implementasi hanya akan dimulai apabila tujuan dan sasaran telah ditentukan. Dengan cara rencana kegiatan telah dibuat dan dipersiapkan untuk mencapai tujuan dan mengalokasikan dana.

Implementasi merupakan suatu kajian mengenai studi kebijakan yang mengarah pada proses pelaksanaan dari suatu kebijakan. Dalam praktek implementasi kebijakan merupakan suatu proses yang begitu kompleks bahkan tidak jarang bermuatan po litis dengan adanya intervensi berbagai kepentingan (Agustino, 2006). Dalam (Wahab, 2012) menguraikan bahwa implementasi sebagaian besar penerapan kebijakan publik atau rencana pemerintah pasti akan melibatkan banyak pengambilan keputusan yang masing masing berusaha untuk mempengaruhi perilaku birokrat atau pejabat lapangan dalam rangka untuk memberikan layanan tertentu kepada publik dan mengatur publik dari satu atau kelompok sasaran. Implementasi kebijakan merupakan suatu tahap diantara diputuskannya suatu kebijakan.

Model implementasi kebijakan Theory George C. Edward III Model implementasi dengan menggunakan pendekatan up down, dalam menganalisis implementasi kebijakan di dalam (Agustino, 2014) terdapat 4 (empat) variabel untuk menentukan keberhasilan implementasi kebijakan, yaitu : Komunikasi, Sumber Daya, Disposisi, dan Struktur Birokrasi . Keempat variabel ini juga terkait satu sama lain 1) Komunikasi, 2) Sumber Daya, 3) Disposisi, Struktur Birokrasi. Kemudian dapat diuraikan lebih lanjut sebagai berikut: 
1. Variabel komunikasi adalah proses informasi mengenai kebijaksanaan dari pelaksanaan tingkat atas kepada aparat pelaksana di tingkat bawahnya.

2. Variabel struktur birokrasi mencakup bagaimana struktur pemerintah, bagian tugas yang ada dan koordinasi yang dilakukan.

3. Variabel sumber-sumber, manusia, informasi, dan sarana prasarana, yang tersedia dalam pelaksanaan kebijakan.

4. Variabel kecendurungan-kecendurungan atau dapat dikatakan sikap atau disposisi aparat pelaksana.

\section{Pelayanan Publik}

Dalam suatu lembaga pemerintahan yang berorentasi pada kesejahteraan rakyat pelayanan publik merupakan satu unsur yang penting. Pelayanan (customer service) adalah suatu bentuk kegiatan yang memberikan kepuasan terhadap pelanggan. Menurut (kanedi dkk, 2017) pelayanan adalah setiap tindakan yang dapat ditawarkan dari satu pihak ke pihak yang lain yang pada hakikatnya tidak berwujud dan tidak mengakibatkan kepemilikan apapun. Dapat kita ketauhi juga bahwa publik adalah masyarakat yaitu kita sendiri, yang mempunyai kewenangan dilayanani, diurus, dan diatur oleh pemerintah itu sendiri.

Pemerintah sebagai administrator namun terkadang pemerintah itu dapat bertindak sebagai penguasa hukum (Kamarni, 2011). Sementara yang dimaksud dengan Pelayanan publik adalah sebagai pemberi layanan atau melayani masyarakat, sesuai dengan aturan pokok atau tata cara yang berlaku. Pemerintah pada kodratnya adalah pelayanan kepada masyarakat, tidak mungkin melayani untuk dirinya sendiri, serta menciptakan suasana atau kondisi yang memungkinkan setiap anggota masyarakat dengan mengembangkan kemampuan demi tercapainya tujuan bersama (Kurniawan , 2016).

Pelayanan publik seringkali merupakan sebuah konsep, dan banyak praktisi dan ilmuwan sering menggunakannya, dan mereka memiliki arti yang berbeda. Dalam sejarah administrasi publik, layanan publik pada awalnya hanya dipahami sebagai layanan yang diberikan oleh pemerintah. Literatur sebelumnya menjelaskan bahwa "Whatever 
goverment does is public service”. Pandangan ini bisa dimaklumi di masa lalu, karena pemerintah hanya mementingkan penyediaan barang atau jasa publik sedangkan menurut kesepakatan politik dan pertumbuhan moral, hal itu dianggap esensial bagi kehidupan warga negara. Namun ketika peran pemerintah dan non-pemerintah dalam memberikan layanan (yang menjadi mata pencaharian banyak orang di era ini ) berubah, maka definisi pelayanan tentang pelayanan publik di atas perlu untuk dipertimbangkan lagi (Dwiyanto, 2017).

Jika kita kaitkan dengan pengertian diatas maka, pemerintah diharuskan memberikan pelayanan yang terbaik kepada masyarakat setidaknya, dalam mewujudkan kepentingan. (Moenir, 2001) berpendapat, Adapun sudut pandang bahwa pelayanan yang baik dan memuaskan berdampak positif kepada masyarakat adalah sebagai berikut: 1) Masyarakat menghormati tenaga kerja.Masyarakat mematuhi peraturan layanan, 2) Masyarakat sangat bangga dengan team dan staff, 3) Masyarakat sangat tertarik dengan bisnis, 4) Mayarakat terus tumbuh dan berkembang untuk membangun masyarakat adil dan makmur yang berlandaskan Pancasila.

\section{METODE PENELITIAN}

Penelitian ini menggunalan penelitian kualitatif. Pada penelitian ini digambarkan secara jelas dan mendatail terkait implementasi pelayanan terpadu satu pintu dalam mewujudkan pelayanan prima di Kantor Dinas Penanaman Modal Dan Pelayanan Terpadu Satu Pintu Kabupaten Trenggalek. Menurut (Sugiyono, 2017) metode penelitian kualitatif adalah penelitian yang digunakan untuk meneliti objek alamiah dimana peneliti adalah sebagai saran utama, teknik pengumpulan data digabungkan bersama, analisis data hasil induktif, dan hasil penelitian kualitatif lebih menekan makna dari pada generalisasi.

Penelitian ini dilakukan di Kabupaten Trenggalek, yakni di Dinas Penanaman Modal dan Pelayanan Terpadu Satu Pintu terkait dengan implementasi pelayanan terpadu satu pintu dalam mewujudkan pelayanan prima. Lokasi ini merupakan kantor dinas yang mengacu pada sektor perizinan dan non-perizinan. Sedangkan Analisis data yang 
digunakan adalah metode Creswell dalam (Afriansah , 2016) yang menyampaikan prosesnya sebagai berikut :

1. Mengolah data dan mempersiapkan data untuk dianalisis. Langkah ini termasuk transkripsi wawancara, men-scanning materi, mengetik data lapangan, memilih dan menyusun data berdasarkan sumber informasi.

2. Membaca keseluruhan data dengan merefleksikan makna secara keseluruhan dan memberikan catatan pinggir tentang gagasan umum yang diperoleh.

3. Menganalisis lebih detail.

4. Penarikan kesimpulan.

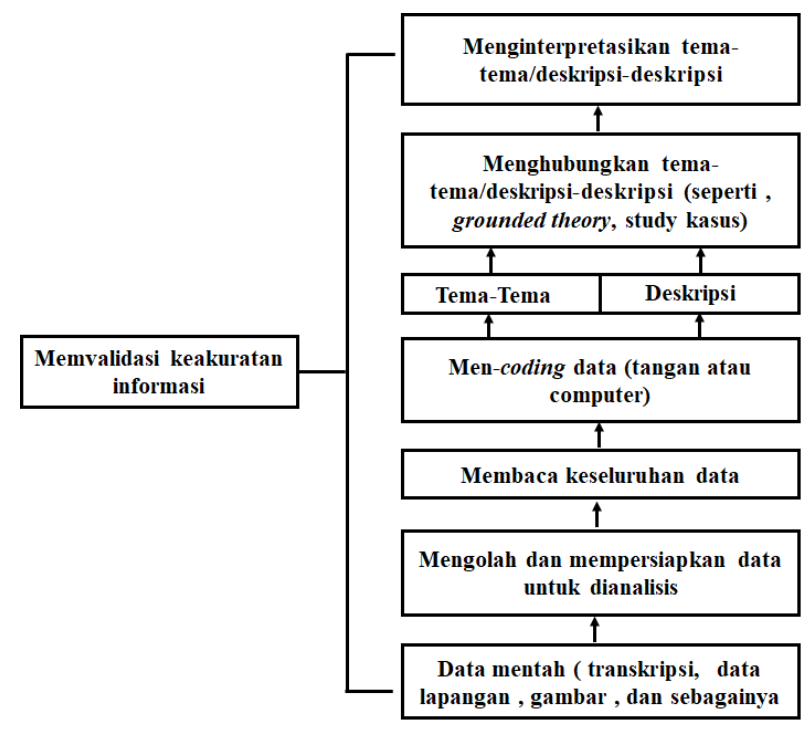

Gambar I. Analisis Data Penelitian Kualitatif

Sumber : (Afriansah , 2016)

\section{PEMBAHASAN}

\section{Komunikasi}

Penyampaian yang dilakukan oleh atasan kepada bawahan terkait implementasi progam PTSP ini dilakukan dengan cara atasan mengumpulkan seluruh staff yang terkait dengan progam implemetasi PTSP dan merapatkan nya bersama-sama. Informasi yang diberikan atasan kepada bawahan sudah dianggaap jelas dan konsistensi. Karena 


\section{MEDIA505IAN}

Jurnal IImu Sosial dan IImu Administrasi Negara Vol.xxx No.xxx Tahun xxx

komunikasi merupakan salah satu variabel penting untuk mempengaruhi implementasi kebijakan. Petugas pun tidak lupa untuk memberikan informasi terkait PTSP di DPMPTSP Kabupaten Trenggalek melalui sosialisai rutin yang telah dilaksanakan selama 1 bulan sekali, namun mengingat di musim pandemic Covid-19 sosialisasi ini dilakukan selama 3 bulan sekali, dengan mematuhi protokol kesehatan.

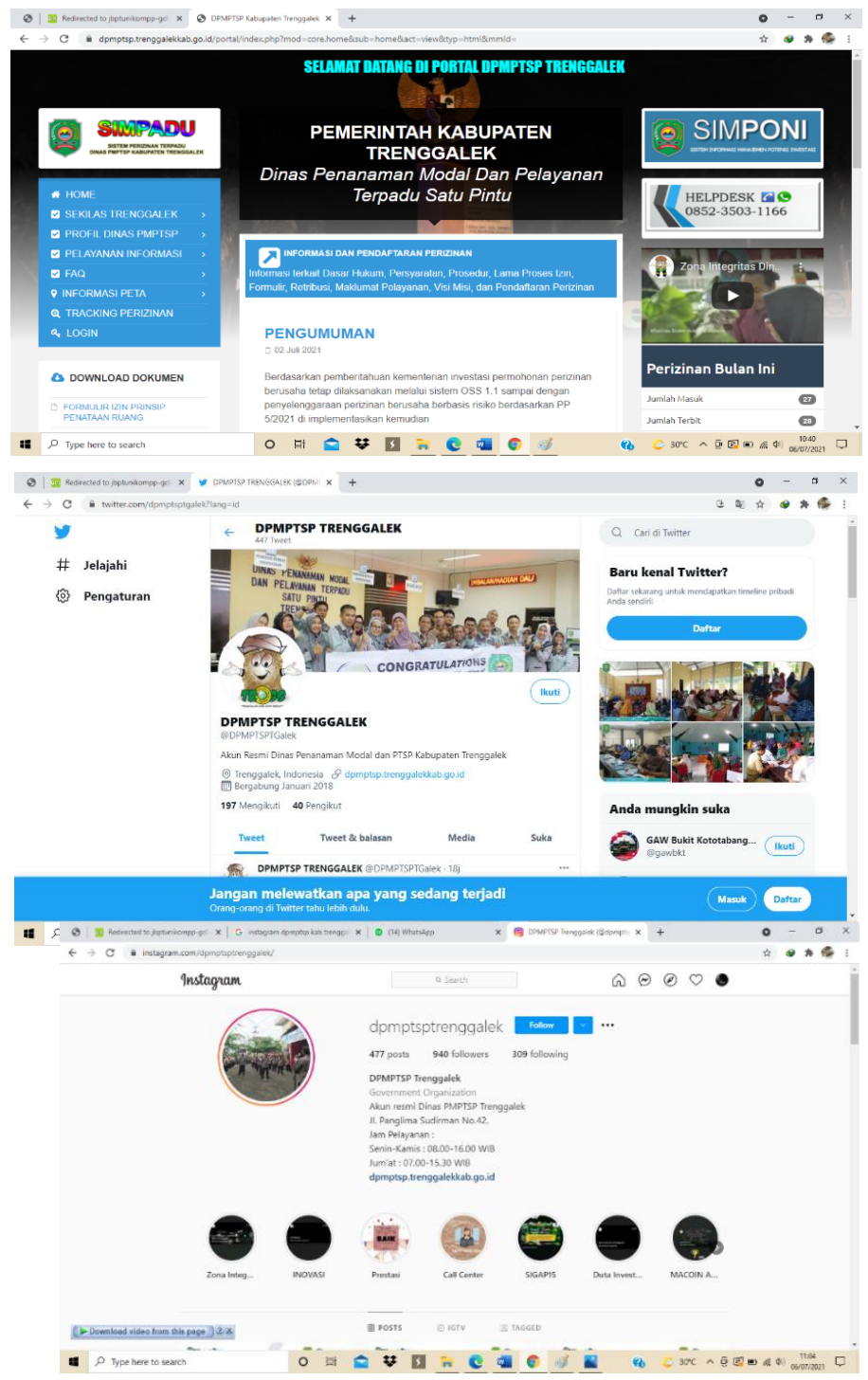

Gambar 2 Sosial Media DPMPTSP Kabupaten Trenggalek Sumber : https://dpmptsp.trenggalekkab.go.id/portal/ 
Sumber daya manusia (SDM) yang dimaksud pada fokus penelitian ini adalah bagaimana cara pengembangan yang dilakukan pegawai dan dilakukannya pelatihan guna untuk meningkatkan kualitas SDM para pegawai DPMPTSP Kabupaten Trenggalek. Sumber daya manusia dalam implementasi kebijakan memegang peranan penting, karena jika tidak tersedia sumber daya manusia dan pendukung lainnya, maka implementasi kebijakan tidak akan efektif. Sumber daya ini berkaitan dengan segala sumber yang dapat digunakan, serta dapat mendukung keberhasilan implementasi PTSP yang ada di DPMPTSP Kabupaten Trenggalek.

Petugas pelayanan yang memiliki kompetensi akan lebih cepat, cekatan, disiplin, dan mahir dalam melayani masyarakat, daripada petugas pelayanan yang kurang berkompetensi. Oleh karena itu, kompetensi setiap petugas pelayanan harus ditetapkan dengan tepat. Pernyataan tersebut sesuai dengan prinsip pelayananpublik menurut Keputusan Menpan No.63/KEP/M.PAN/7/2003,yaitu "Kedisiplinan, kesopanan, dan keramahan; Pemberi pelayanan harus bersikap disiplin, sopan dan santun, ramah serta memberikan pelayanan dengan ikhlas (Alfiyani, 2020).

Kesuksesaan suatu pelayanan faktor pendukungnya salah satunya adalah dengan adanya kemampuan dari petugas dalam menjalankan pelayanan. Keseriusan aparatur dalam menjalankan tugasnya merupakan suatu bentuk dimana para aparatur melakukan interaksi dengan baik dengan masyarakat maka dengan sendirinya masyarakatpun memberikan kepercayaan kepada aparatur dalam melayani masyarakat dengan layananlayanan yang dibutuhkan masyarakat. Kebutuhan masyarakat merupakan tugas yang harus dapat dilaksanakan oleh aparatur dalam dengan hasil pekerjaan sesuai dengan harapan, atau bahkan melebihi harapan masayarakat sehingga masyaratat merasakan kepuasan pelayanan. Kepuasan masyarakat adalah tanggapan masyarakat atas terpenuhinya kebutuhan yang berarti bahwa penilaian masyarakat atas pelayananan yang diberikan oleh aparatur memberikan tingkat kenyamanan yang terkait dengan pemenuhan suatu kebutuhan para masyarakat.

\section{Disposisi}

Copyright@2020; Jurnal Mediasosian - pISSN: 2579-342X, elSSN: 2620-5149| 209 
Disposisi adalah sikap dan komitmen dari pelaksana terhadap kebijakan atau program yang harus dilaksanakan oleh seluruh aparat DPMPTSP Kabupaten Trenggalek karena setiap kebijakan membutuhkan pelaksana-pelaksana yang memiliki hasrat kuat dan komitmen yang tinggi agar mampu mencapai tujuan kebijakan yang diharapkan. Dilihat dari faktor disposisi maka dapat dikatakan bahwa dalam penerapan program Pelayanan Terpadu Satu Pintu (PTSP) di DPMPTSP Kabupaten Trenggalek, sudah bersikap adil kepada masyarakat dalam memberikan pelayanan, dan tidak ada membeda-bedakan pelayanan, karena DPMPTSP Kabupaten Trenggalek lebih mengutamakan masyarakat dari pada kepentingan pribadi.

Pengetahuan merupakan apa yang di ketahui dari setiap masing-masing aparatur berhubungan dengan prodak pelayanan yang diberikan. Selain itu pengetahuan merupakan gambaran dari aparatur bagaimana aparatur dapat melayani masyarakat sesuai dengan apa yang di tetapkan oleh Dinas Penanaman Modal dan Pelayanan Terpadu Satu Pintu (DPMPTSP) Kabupaten Trenggalek untuk memberikan nilai yang positif terkait dengan pelayanan yang diberikan maka aparatur pun di tuntut untuk memahami apa yang dimaksud dengan pelayanan perizinan. Pengetahuan aparatur dalam menjelaskan bagaimana proses pembuatan dan pendftaran online harus sangat baik, apabila pengetahuan aparatur tidak benar maka perizinan ini tidak akan berjalan dengan baik. Pengetahuan yang baik di dalam bidang pelaksanaan tugas merupakan solusi dari suatu pelayanan yang diberikan terjadi karena profesional dalam memberikan pelayanan. Terjadinya pelayanan baik merupakan keutaman dalam menjalankan tugas-tugasnya.

\section{Struktur Birokrasi}

Struktur birokrasi DPMPTSP Kabupaten Trenggalek yang secara jelas mengatur, seluruh tugas dan fungsi yang diperlukan dan kewenangan setiap Unit kerja/SKPD terkait dan personil, serta mengatur pemisahan fungsi dan kewenangan sesuai dengan tugas pokok dan fungsi yang telah ditentukan sebagai dasar untuk pelaksanaan tugas yang sudah

tertuang dalam Peraturan Bupati (PERBUP) Nomor 27 Tahun 2017 Tentang Penjabaran 
Tugas Dinas Penanaman Modal Dan Pelayanan Terpadu Satu Pintu (PERBUP, 2017). Struktur birokrasi dalam pemerintahan memiliki ciri yaitu adanya Standar Pelayanan (SP) dan Standar Operasional Prosedur (SOP) menjadi pendukung dalam implementasi kebijakan dimana mekanisme implementasi menjadi lebih jelas dan menjamin kesamaan implementasi kebijakan PTSP. Seperti wawancara yang sudah saya lakukan kepada Standar operasional prosedur merupakan tahapan yang dilalui untuk menyelesaikan tugas pelayanan di DPMPTSP Kabupaten Trenggalek. SOP perizinan, sebagai panduan dalam pelaksanaan tugas pelayanan untuk pemberian izin kepada orang pribadi atau badan usaha yang dimaksudkan untuk pembinaan, pengaturan, pengendalian dan pengawasan atas kegiatan.

\section{KESIMPULAN DAN SARAN}

Berdasarkan hasil penelitian yang dilakukan, peneliti menarik kesimpulan sebagai berikut : Secara keseluruhan proses pengurusan perizinan di Dinas Penanaman Modal Dan Pelayanan Terpadu Satu Pintu Kabupaten Trenggalek seperti pelayanan perizinan IMB, SIUP, izin lokasi, izin reklame dan lain sebagainya meliputi dari alur proses perizinan dimulai dari pertama pemohon mengambil formulir yang sudah di sediakan oleh pihak pelayanan, kemudian pemohon mengisi dan melengkapi persyaratan administrasi lalu pemohon mengumpulkan formulir beserta persyaratannya, kemudia petugas pelayanan akan memberikan kepada petugas yang sesuai dengan izin yang pemohon urus, selanjutnya setelah petugas tersebut membuat surat izinnya lalu dicek oleh bagian pengawasan untuk dicek surat izinnya kemudian diberi no registrasi selanjutnya diberikan kepada petugas

Mengenai waktu, Dinas Penanaman Modal Dan Pelayanan Terpadu Satu Pintu Kabupaten Trenggalek telah menetapkan waktu untuk masing-masing perizinan yang tertulis di dalam SOP. Untuk mengenai biaya perizinan di Dinas Penanaman Modal Dan Pelayanan Terpadu Satu Pintu Kabupaten Trenggalek dari 36 jenis perizinan hanya 
perizinan izin mendirikan bangunan (IMB) dan Izin usaha perikanan di bidang pembudidayaan ikan yang dikenai biaya sesuai dengan PERDA Kabupaten Trenggalek.

\section{REFERENCES}

Afriansah . (2016). Penggunaan Software ATLAS.ti Sebagai Alat Bantu Proses Analisis Data Kualtatif. Pendidikan Matematika , 56.

Agustino. (2006). Analisis Kebijakan Publik. Jakarta: Rineka Cipta.

Akib. (2010). Implementasi Kebijakan. Administrasi Publik, 2.

Alfiyani. (2020).

Dwiyanto. (2017). Manajemen Pelayanan Publik (2nd ed.). Yogyakarta: Gadjah Mada University Press, Anggota IKAPI, Anggota APPTI.

Ginting dkk. (2018). IMPLEMENTASI PELAYANAN TERPADU SATU PINTU NONPERIZINAN DIUKUR DARI KEPUASAN MASYARAKAT DENGAN MENGGUNAKAN INDEKS KEPUASAN MASYARAKAT. Responsive, I, 4555.

Kamarni. (2011). Analisis pelayanan publik terhadap masyarakat. Manajemen dan Kewirausahaan, III, 89.

kanedi dkk. (2017). sistem untuk peningkatan kepuasan pengunjung pada perpustakan arsip dan dokumentasi kota Bengkulu. Pseudocode, $I V, 38$.

Kurniawan . (2016). Tantangan kualitas publik pada pemerintah daerah. Adminitrasi Publik dan pembangunan, VII, 16.

Moenir. (2001). Manajemen Pelayanan Umum di Indonesia (5nd ed.). Jakarta: Bumi Aksara.

PERBUP. (2017).

Sabatier. (1986). Top-Down and Bottom-Up Approaches to Implementation Research: a Critical Analysis and Suggested Synthesis. Public Policy, 21-48.

Sugiyono . (2017). Metode Penelitian Kuantitatif, Kualitatif . Bandung: Alfabeta.

Supriyatno. (2020). Kabupaten Trenggalek Raih Empat Penghargaan. Retrieved Februari Jum'at, 2021

Copyright@2020; Jurnal Mediasosian - pISSN: 2579-342X, elSSN: 2620-5149| 212 
Wahab. (2012). Analisis Kebijakan dari formulasi ke penyusunan model-model Implementasi Kebijakan Publik. Jakarta: Bumi Aksara.

Widodo. (2020). Lomba Inovasi Tatanan Normal Baru, Trenggalek Borong 4 Penghargaan. Trenggalek: KOMPAS.com. 